\title{
The Biological Significance of Conjugate Nuclei in Coprinus lagopus and other Hymenomycetes.*
}

By Prof. A. H. Reginald Buller, F.R.S.

CONJUGATE nuclei are two nuclei of opposite $\cup$ sex, associated with one another in a single cell, which divide sumultaneously in such a way as to give rise to two daughter pairs of conjugate nuclei. Stages in conjugate nuclear division in Coprinus lagopus, based on the work of Mlle. Bensaude, are shown in Fig. 7.

In animals conjugate nuclei are unknown and in plants their occurrence is limited to the Higher Fungi. They especially characterise the diploid mycelium and fruit-bodies of the Hymenomycetes (Mushrooms and Toadstools) and the diploid mycelium of the Rust Fungi and the Smut Fungi, all of which groups are included in the larger assemblage of the Basidiomycetes. Conjugate nuclei

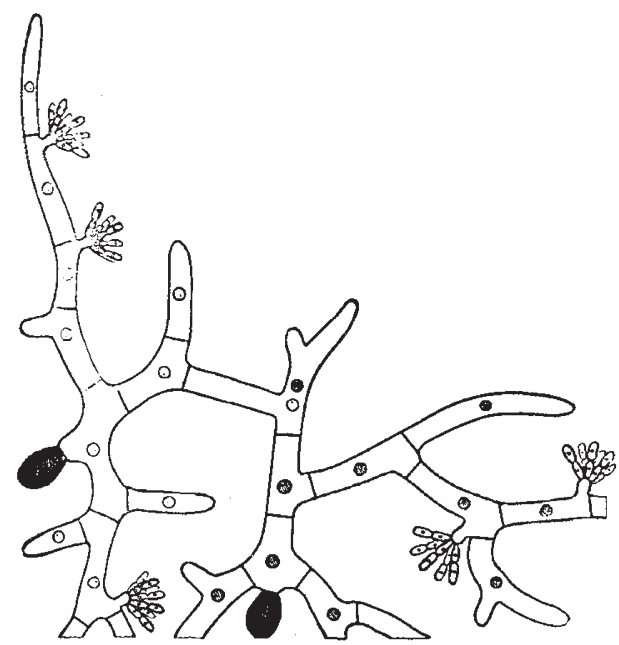

Fra. 1.-Coprinus lagopus. Diagram showing two haploid mycelia of opposite sex, $(A B)$ on right (black nuclei), $(a b)$ on left (white nuclei), each derived from a single basidiospore. Note the simple septa, the gromps of oidia, and the isolated nuclei. The two mycelia have just effected a hyphal fusion and in the fusion cell an $(A B)$ nuclens and an $(a b)$ nucleus have become associated as a pair of conjugate nuclei. The diploid cell is able to diploidise all the other cells of both mycelia by a process illustrated in Fig. 6 .

are also present in the ascogenous hyphæ of certain Ascomycetes.

Coprinus lagopus is a small toadstool of common occurrence on horse dung in pastures. Its pilei shed numerous black basidiospores which are carried off by the wind, settle on grass, etc., are swallowed with herbage by horses, and germinate in freshly deposited dung-balls. In these dungballs haploid mycelia of opposite sex mate with one another and form diploid mycelia. The diploid mycelia give rise to diploid fruit-bodies which produce and liberate haploid basidiospores. The life-cycle from spore to spore is carried through in 10-14 days.

As determined by Hanna, ${ }^{1}$ Dorothy Newton, ${ }^{2}$ and others, the monosporous mycelia (each derived from a single basidiospore) of Coprinus lagopus fall into four groups. If it be assumed that each

- Substance of a paper communicated to a meeting of the Fifth International Botanical Congress at Cambridge, Aug. 19, 1930. mycelium bears one of each of two pairs of sex factors, $A a$ and $B b$, then the four groups of mycelia and the four groups of spores from which they have

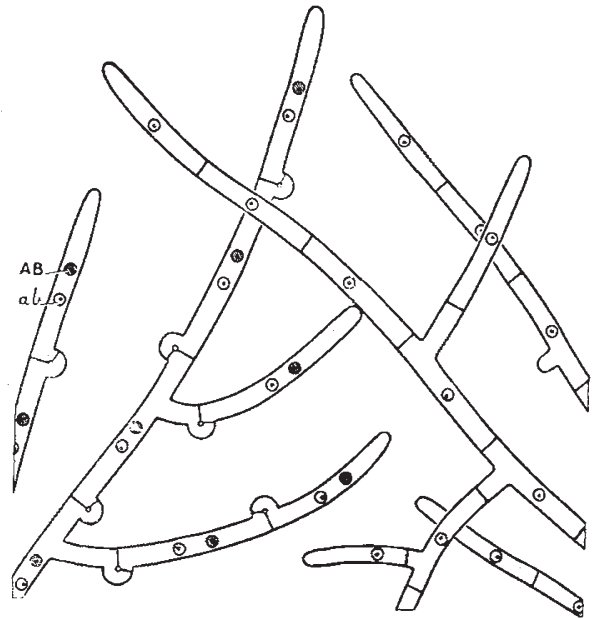

FIG. 2.-Coprinus lagopus. A diploid mycelium $(A B)+(a b)$ on the left, and a haploid mycelium $(a b)$ on the right. In the diploid mycelium, note the pairs of conjugate nuclei of opposite sex in each cell and the clamp-connexion at each septum. A central hypha of the diploid mycelium is about to fuse with a hypha of the haploid mycelium. The diploid mycelium, after the fusion was effected, would begin to diploidise the haploid mycelium.

been derived may be represented by the symbols $(A B),(a b),(A b)$, and $(a B)$.

Successful mating of the haploid mycelia of Coprinus lagopus with the production of a diploid mycelium (bearing clamp-connexions and containing a conjugate pair of nuclei in each cell) is

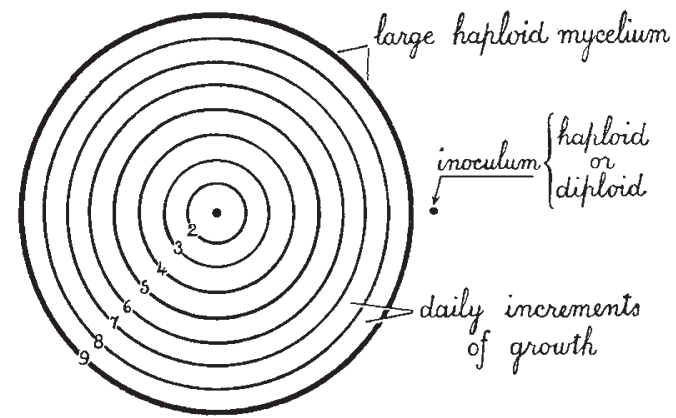

FrG. 3.-Coprinus lagopus. A large haploid mycelium which has been growing for 9 days on dung-agar. A tiny hyphal mass of another haploid mycelium of opposite sex or of a suitable diploid mycelium, phery of the large haploid mycelium.

normally possible only in the combinations $(A B) \times$ $(a b)$ and $(A b) \times(a B)$. These two kinds of combinations give rise to two kinds of diploid mycelia which may be represented by the symbols $(A B)+$ $(a b)$ and $(A b)+(a B)$ respectively.

Haploid mycelia (Fig. 1) are known by containing single isolated nuclei, by having simple septa devoid of clamp-connexions, by the wideangled mode of branching of their leading hyphæ, and by bearing oidia. Diploid mycelia (Fig, 2,

No. 3183 , VoL. 126] 
left) are known by their cells containing pairs of | course of three days. In 42 hours after the (ab) conjugate nuclei, by having a clamp-connexion inoculum had been deposited and about 40 hours at each septum, by the narrow-angled mode of branching of their leading hyphæ, and by not bearing oidia. Clamp-connexions, as shown by the cytological investigations of Mlle. Bensaude, Hans Kniep, and others, are the outward and visible sign that the adjacent cells are diploid in that these cells contain a pair of nuclei of opposite sex.

A large haploid mycelium $(A B)$, which had been growing on a dung-agar plate for 9 days (cf. Fig. 3), was inoculated with a small hyphal mass of a haploid mycelium $(a b)$. The two mycelia soon fused hyphally and mutually diploidised one another, that is, $(a b)$ nuclei entered the mycelium $(A B)$, divided and subdivided, and established pairs of conjugate nuclei $(A B)+(a b)$ in every cell of the peripheral hyphæ of $(A B)$, while $(A B)$ nuclei entered the mycelium $(a b)$, divided and subdivided, and established pairs of conjugate nuclei $(A B)+(a b)$ in every cell of the peripheral hyphæ of $(a b)$. This was indicated by the appearance of clamp-connexions. In the large haploid mycelium $(A B)$, clamp-connexions appeared on the $(A B)$ hyphæ on each side of the inoculum $(a b)$ progressively (vide crosses in Fig. 4); and the diploidisa-

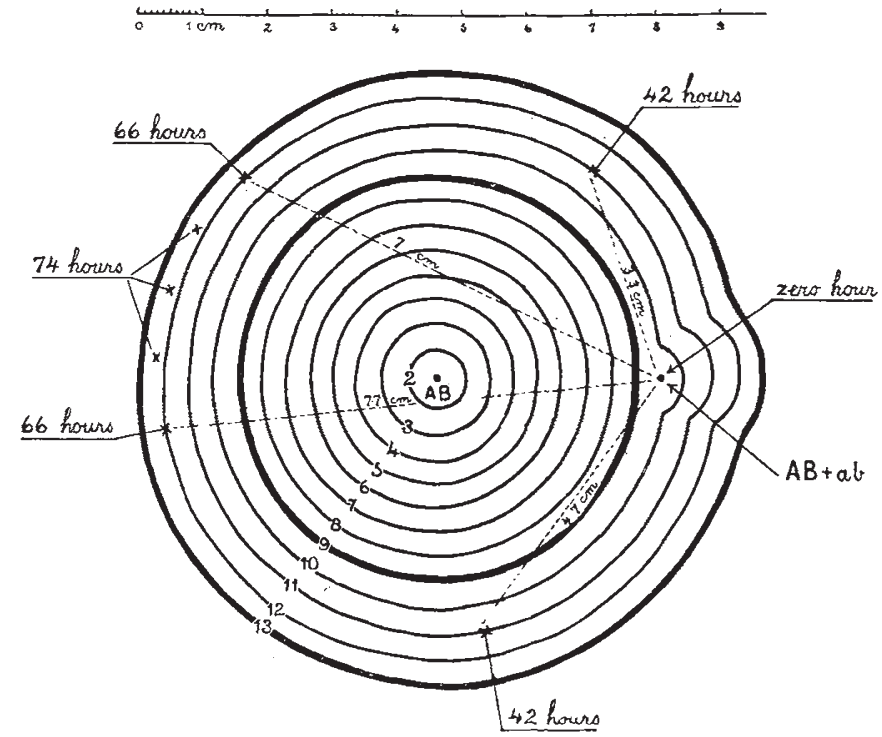

FrG. 5.- The diploidisation of a large haploid mycelium $(A B)$ by a diploid mycelium $(A B)+(a b)$. The $(A B)$ mycelitum was inoculated with a tiny hyphal mass of the $(A B)+(\alpha b)$ mycelium after 9 days of growth (periphery shown by heavier inner circle, No, 9) at the zero hour. The diploid mycelium dipioidised the haploid mycelium in a little more than three days. The crosses show where clamp-connexions were observed at particular times. The $(a b)$ nuclei must about 64 hours, or more than $1.2 \mathrm{~mm}$. per hour. Two-thirds the actual size.

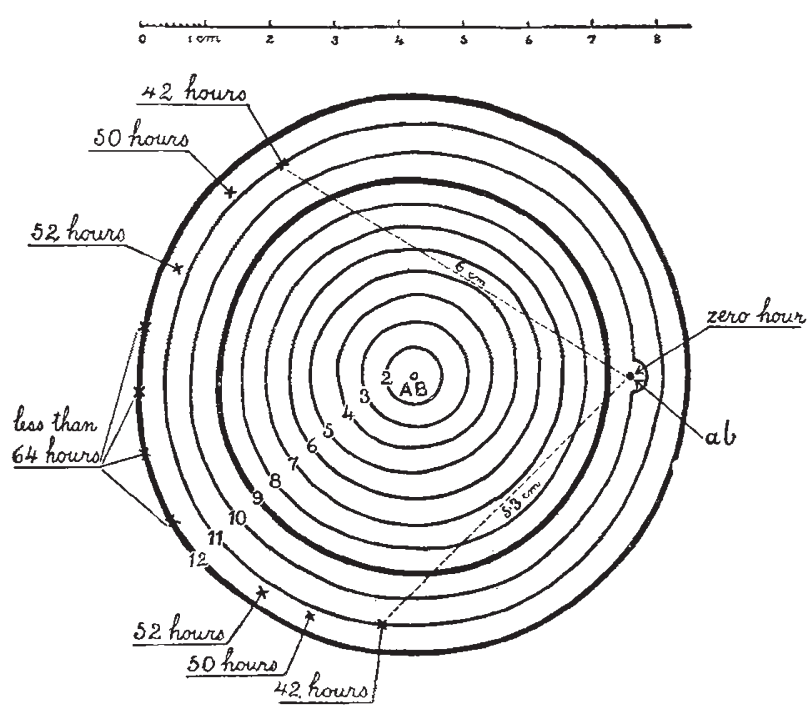

FIt. 4.-The diploidisation of a large haploid mycelium $(A B)$ by another haploid mycelium $(a b)$ of opposite sex. The circles $2-12$, originally drawn in blue pencil on the under side of the Petri dish, show the boundary of the mycelium from the end of the second to the end of the twelfth day. The $(A B)$ mycelium was inoculated with a tiny hyphal mass of an $(a b)$ mycelium after 9 days of growth (periphery shown by heavier inner circle, No. 9) at the zero hour. The $(a b)$ mycelium diploidised the $(A B)$ mycelium in the course of three days. The crosses show where clampconnexions were observed at particular times. The $(a b)$ nuclei must have travelled more than $6 \mathrm{~cm}$. or $60 \mathrm{~mm}$. through the $(A B)$ hyphæ in about 40 hours, or more than $1.5 \mathrm{~mm}$. per hour. Two-thirds the actual size.

tion $\dagger$ of the $(A B)$ mycelium was effected in the $\dagger$ The term diploidisation has been introduced here for the first time to designate the process by which a haploid cell is converted into a diploid cell or a haploid mycelium into a diploid mycelium by the formation of conjugate nuclei within the cell's or the mycelium's interior. A haploid mycelium of one sex may be said to diploidise a haploid mycelium of opposite sex.

No. 3183, VoL. 126] after the $(a b)$ and $(A B)$ mycelia had come into contact with one another, clamp-connexions had appeared at a distance of $6 \mathrm{~cm}$. or $60 \mathrm{~mm}$. from the inoculum. 'Therefore $(a b)$ nuclei must have moved through the hyphæ of the $(A B)$ mycelium at an average rate of at least $1.5 \mathrm{~mm}$. per hour. The nuclei could not move in a straight line like that shown in Fig. 4, because the mycelium $(A B)$ was a three-dimensional hyphal net-work. The $(a b)$ nuclei must have taken a zigzag path and, therefore, their speed of movement doubtless exceeded $2 \mathrm{~mm}$. per hour. As Lehfeldt's cytological work on Typhula erythropus has shown, ${ }^{3}$ the septa of a haploid mycelium undergoing diploidisation break down and thus allow nuclei to pass along the hyphæ.

The radial rate of growth of the $(A B)$ mycelium of Fig. 4 was $0.15 \mathrm{~mm}$. per hour. Therefore the rate of movement of the $(a b)$ nuclei along the hyphr of the $(A B)$ mycelium -upwards of $2.0 \mathrm{~mm}$. per hour-was more than thirteen times the rate of elongation of the leading radial $(A B)$ hyphæ.

Fig. 5 illustrates an experiment similar to that just described, except for the important fact that a diploid inoculum was employed instead of a haploid. The combination was a large haploid mycelium $(A B)$ and a small diploid inoculum $(A B)+(a b)$. Again the large haploid mycelium was progressively diploidised. In this case, doubtless, $(a b)$ nuclei left the diploid inoculum, entered the $(A B)$ mycelium, there divided and subdivided, and so provided mates 
to form conjugate pairs with all the $(A B)$ nuclei in the peripheral hyphæ of the $(A B)$ mycelium.

It has been found that a diploid mycelium $(A B)+(a b)$ can rapidly diploidise a haploid mycelium $(A B)$ or a haploid mycelium $(a b)$; and also that a
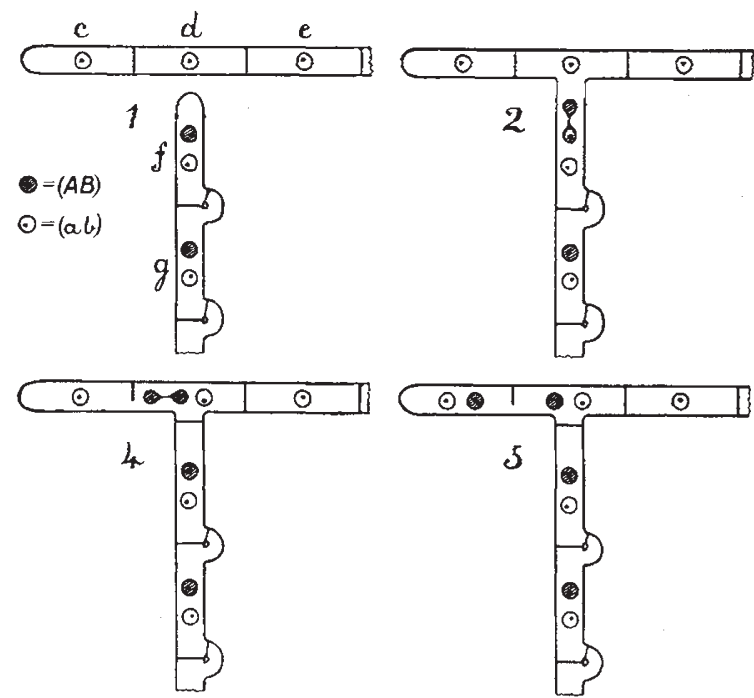

FIG. 6.-Diagram to show the diploidisation of a baploid mycelium $(a b)$ by a diploid mycelium $(A B)+(a b)$. No. 1 : the cell $f$ of the diploid hypha $f_{y}$ is growing toward, and soon will meet and fuse with, the cell $d$ of the haploid hypha $c$ de. No. 2 : fusion has taken place and the $(A B)$ nucleus of $f$ is dividing. No. 3: one of the daughter $(A B)$ nuclei has passed into the cell $d$, thus diploidising it. No. $4:$ a wall now separates the cells $d$ and $f$, and the $(A B)$ nucleus in the cell $d$ is dividing. No. 5 : the wall between the cells $c$ and $d$ is partly broken down and one of the daughter $(A B)$ nuclei has passed through it from $d$ to $c$. No. 6: the $(A B)$ nucleus of the cell $d$ has ggain divided and sent one of its daughter $(A B)$ nuclei into the cell $e$. Thus the diploid cell $f$ diploidised the haploid cell $d$ and the diplota cell $d$ in its turn diploidised furs the haploid cell $c$ and then the haploin cell $\&$

diploid mycelium $(A b)+(a B)$ can rapidly diploidise a haploid mycelium $(A b)$ or a haploid mycelium $(a B)$.

The discovery that a diploid mycelium can diploidise an appropriate haploid mycelium is of considerable interest from two points of view: (1) It indicates that, in Coprinus lagopus and other similar fungi, the normal matings in dung-balls, wood, and other substrata in Nature are not merely the haploid matings $(A B) \times(a b)$ and $(A b) \times(a B)$ but are also the haploid-diploid matings $(A B) \times$ $(A B)+(a b), \quad(a b) \times(A B)+(a b), \quad(A b) \times(A b)+(a B)$, and $(a B) \times(A b)+(a B)$; and $(2)$ it also indicates that a diploid cell containing a pair of conjugate nuclei can diploidise a haploid cell containing a single nucleus, and thus gives us a clue to the biological significance of conjugate nuclei. This last point will now be discussed.

When, in a haploid-diploid combination, a diploid cell containing a pair of conjugate nuclei, say $(A B)+(a b)$, comes into contact with a haploid cell containing a single nucleus, say $(a b)$, doubtless the $(A B)$ nucleus-possibly in response to a stimulus received from the unpaired $(a b)$ nucleus-divides and sends off one of the daughter nuclei into the haploid cell (Fig. 6, stages 2 and 3). Thus, in a very simple way, a diploid cell can diploidise a haploid cell. Doubtless, also, when a large haploid mycelium has been inoculated with a tiny hyphal haploid inoculum of opposite sex, the progressive diploidisation of the large haploid mycelium is due essentially to the fact that a diploid cell is able to

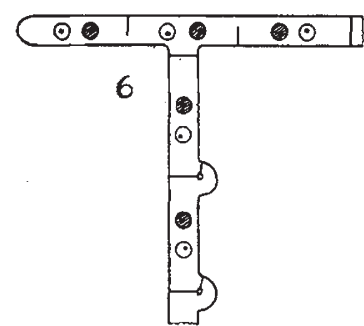

diploidise neighbouring haploid cells in the manner ust suggested (cf. Fig. 6, stages 3-6).

If, when a large haploid mycelium $(A B)$ made a hyphal fusion with a small haploid inoculum of opposite sex $(a b)$, an $(a b)$ nucleus on passing into an $(A B)$ cell immediately fused with the $(A B)$ nucleus there present, an $(A a B b)$ nucleus would result and progressive diploidisation of the thousands of other $(A B)$ cells the $(A B)$ nuclei of which awaited partners would be impossible. However, since the $(a b)$ nucleus is attracted by, but does not fuse with, the first $(A B)$ nucleus it meets, it is possible for it to divide and send off a daughter $(a b)$ nucleus into the next haploid $(A B)$ cell and thus contribute to the diploidisation process.

The organisation of the nuclei in conjugate pairs $(n)+(n)$ instead of as isolated nuclei $(2 n)$ in the diploid mycelium and fruit-body of Coprinus lagopus and other Hymenomycetes results, it is true, in delaying the fusion of nuclei of opposite sex until the
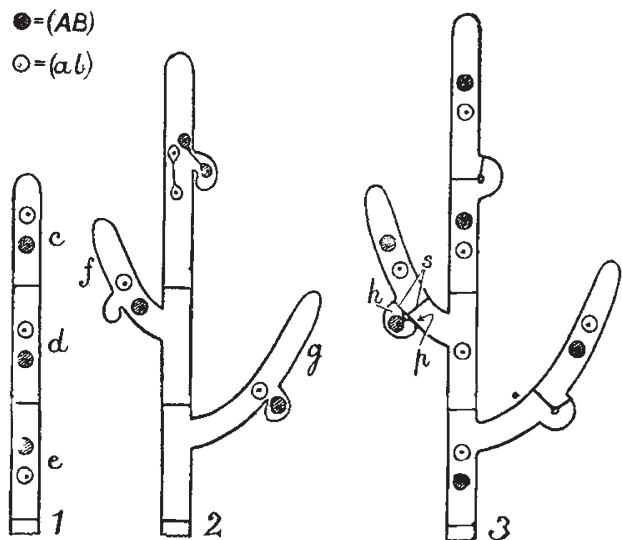

FIt. 7.-Diagram to show how a haploid hypha after it has just been diploidised develops further. No. $1:$ a haploid hypha $(a b)$ or $(A B)$ which has just been converted into a diploid hypha $(A B)$ $+(a b)$; a pair of conjugate nuclei are present in each cell. No. 2: the cells $d$ and $e$ have branched and the cell $c$ has elongated; in $f$ a hook has grown backwards; in $g$ an $(A B)$ nucleus has passed into the hook; in the terminal cell $c$, the two nuclei are dividing conjugately and the hook is growing toward the main hypha. No. 3 : in the branch $f$ the two daughter pairs of conjugate nucle have separated from one another and two septa 8 have been formed but the lower $(A B)$ nucleus is momentarily a prisoner in the hook-cell $h$, from which it will escape as soon as the walls at have broken down; in the branch $g$ and the terminal cell $c$ conjugate nuclear division and cell-division with the formation of a clamp-connexion is complete and each daughter cell contains a pair of conjugate nuclei $(A B)$ and $(a b)$.

basidia come into existence, but it has the great advantage that, in the diploid mycelium or in a diploid cell of a haploid mycelium under-

No. 3183 , VoL. 126] 
going diploidisation, each member of a pair of conjugate nuclei retains its identity, so that one member of a pair can divide independently of the other member of the pair whenever such a division is able to promote the diploidisation of another haploid mycelium or of an adjacent haploid cell.

The sexual process (fertilisation or conjugation) of animals and most plants is relatively simple in that two unicellular and uninucleate gametes fuse to form a unicellular and uninuclear zygote. On the other hand, in the Hymenomycetes the sexual process is more complicated, because it takes place between multicellular and multinucleate mycelia and results in the diploidisation of all the growing cells of each mycelium. It is the non-fusion of nuclei of opposite sex and the establishment of conjugate pairs of nuclei which makes this diploidisation possible.

The development of a haploid hypha $(a b)$ or $(A B)$, which has just become diploidised owing to the entry into it of nuclei derived from either a haploid mycelium of opposite sex or from a diploid mycelium $(A B)+(a b)$, is shown in Fig. 7, where it will be seen that, as the cells grow in length or branch, conjugate nuclear division takes place, and that each conjugate nuclear division is accom- panied by the formation of a clamp-connexion. When, in a dung-ball, a diploid mycelium of Coprinus lagopus, like that shown in Fig. 7, stage 3 , meets a haploid mycelium $(A B)$ or $(a b)$ of the same species (cf. Fig. 2) the diploid and the haploid mycelia doubtless fuse hyphally and the diploid mycelium diploidises the haploid mycelium ( $c f$. Fig. 6), thus increasing the chances that one or more vigorous diploid fruit-bodies developing all the possible sexual kinds of spores $(A B),(a b),(A b)$, and $(a B)$ will be produced rather than one or more relatively feeble haploid fruit-bodies developing only one of the four possible sexual kinds of spores. There can be no doubt that, in Coprinus lagopus and in other similar Hymenomycetes, the diploidisation of haploid mycelia by appropriate diploid mycelia is a distinct aid to reproduction."

In conclusion, the author desires to acknowledge a grant in aid of the work made by the Research Council of Canada and valuable assistance in making the experiments given by Miss Ruth Macrae.

${ }^{1}$ W. F. Hanna, "The Problem of Sex in Coprinus lagopus", Annals of Botany, vol. 39, pp. 431-457; 1925.

2 Dorothy Newton, "The Distribution of Spores of Diverse Sex on the Hymenium of Coprinus lagopus ", ibid., vol. 40, pp. 891-917; 1926. ${ }^{3}$ W. Lehfeldt "tther die Fntstehung des Paarmycels bei heterothallischen Basidiomyceten", Bedroigia, Bd. 64, pp. 30-51; 1922 .

4 A fuller discussion of conjugate nuclei has been prepared for vol. 4 of the author's " Researches on Fungi ".

\section{Recent Hydro-Electric Developments in Switzerland.}

\section{By Dr, Brysson Cunningham.}

$\mathrm{F}^{\mathrm{n}}$ ROM the report for 1929 of the Swiss Service des Eaux, it is to be gathered that developments of hydro-electric energy have been prosecuted during recent years with unabated enterprise and zeal. There was merely a slight falling-off during 1929 in the productive capacity of the power stations, due essentially to the intense cold in the early part of the year and to depletion of the water supplies in the autumn. The returns show a total of 4178 million k.w.h. as compared with 4410 million k.w.h. and 4350 million k.w.h. in the two years immediately preceding. The adverse conditions necessitated recourse in a large measure to the supplies of water stored in the lakes, and the deficit was only made good towards the end of the year.

The most important installation put into operation during 1929 was the power station at Handeck, in connexion with the river Aar, an undertaking of the Forces Motrices de l'Oberhasli S.A., Innertkirchen. This has a present capacity of 60,000 horse power, with an ultimate possibility of 120,000 horse power. Among projects still in course of construction at the end of the year may be mentioned an installation on the Dixence in the Canton of Valais, of 175,000 horse power, and another of 50,000 horse power at Monte Piottino in the Canton of Ticino. An installation of 140,000 horse power at Ryburg-Schwörstadt on the Rhine will be partially Swiss.

It is computed that, on Jan. 1 last, the power stations in Switzerland, either in operation or in course of construction, aggregated a total capacity of about 2,700,000 horse power. Some of these stations are of considerable individual capacity, among them being those of Vernayaz (Canton Valais) for the Swiss Federal Railway, 108,000 horse power; Wäggital (Zurich), 90,000 horse power; Löntsch (Glarus), 66,000 horse power; and Laufenburg (Rhine), 65,000 horse power.

A recent visit to the Engadine brought me into close proximity with a number of hydro-electric installations which have materialised during the past quarter of a century. The district is particularly rich in sites affording scope for power development and some of these have now been exploited almost to the full extent of their capacity. One of the most striking examples, which I had an opportunity of inspecting, is the undertaking of the Brusio Power Company, which has its headquarters at Poschiavo in the extreme south of the Canton of the Grisons and within a short distance of the Swiss-Italian frontier.

The series of stages by which the Brusio Power Company develops the hydraulic capacity of the southern slopes of the Bernina Range and the Poschiavo Valley commences at the summit level of the Bernina Pass, where there are two sheets of water forming a natural reservoir for impounding purposes at a level of 2200 metres above the sea. The two sheets of water, more or less frozen, of course, during a considerable part of the year, are Lago Bianco (White Lake) and Lago della Scala (the precise signification of which between 'staircase ', 'scale ', 'succession', and 'landing-place' is not easy to determine). The former is much the larger of the two, but they are so closely adjacent within a common depression as essentially to form

No. 3183, VoL. 126] 